\title{
Application of cross-hole electrical resistivity tomography to groundwater contaminated remediation site
}

\author{
Tzu-Pin Wang ${ }^{1,2, *}$, Yao-Tsung Chen ${ }^{3}$, Chien-Chih Chen ${ }^{4}$, Tien-Hsing Tung ${ }^{2,3}$, Shih-Nan Cheng ${ }^{1,5}$, and \\ Chun-Yi $\mathrm{Yu}^{5}$
}

\author{
${ }^{1}$ Disaster Reduction Research Center, Chien Hsin University of Science and Technology, Taoyuan City, Taiwan \\ ${ }^{2}$ Geophysical Technology and Engineering Co., Ltd., Taipei City, Taiwan \\ ${ }^{3}$ Apollo Technology Co., Ltd., Taipei City, Taiwan \\ ${ }^{4}$ Department of Earth Sciences, National Central University, Taoyuan City, Taiwan \\ ${ }^{5}$ Department of Applied Geomatics, Chien Hsin University of Science and Technology, Taoyuan City, Taiwan
}

\section{Article history: \\ Received 21 August 2018 \\ Revised 4 March 2019 \\ Accepted 17 June 2019}

Keywords:

ERT, CHERT, Resistivity, Pollution, Groundwater contamination, NAPL,

Remediation, Time lapse

\section{Citation:}

Wang, T.-P., Y.-T. Chen, C.-C. Chen, T.-H. Tung, S.-N. Cheng, and C.-Y. $\mathrm{Yu}, 2020$ : Application of cross-hole electrical resistivity tomography to groundwater contaminated remediation site. Terr. Atmos. Ocean. Sci., 31, 507-521, doi: 10.3319/ TAO.2019.06.17.01

\begin{abstract}
Time-lapse methodology was applied to cross-hole electrical resistivity tomography (CHERT) to investigate two groundwater contamination sites. In the first case study, resistivity profiles were used to delineate the transport direction and spatial distribution of the contaminant, which can serve as a basis for adjusting the remediation treatment by the remediation team. In the second case study, changes in electrical conductivity were used to evaluate the remediation reagent's transport direction and area of effect, and this was used to indirectly verify the effectiveness of the remediation efforts. CHERT equipment was installed simultaneously at the monitoring wells, which enhanced the benefits of the boreholes, enabling them to be even more economical. In large-scale groundwater contamination sites or sites with complex hydrogeological environments, application of CHERT techniques can result in greater amounts of data, particularly in analyzing localized preferential flow paths. This data would be greatly beneficial to the remediation of groundwater contamination sites and long-term groundwater management.
\end{abstract}

\section{INTRODUCTION}

The first critical issue encountered in treating groundwater contamination sites is how to delineate the distribution of contaminants. Sample analysis is the most direct and accurate method. However, if the site covers an extensive area or contains highly heterogeneous geological material, and/ or if the contaminant source is unknown, no number of drill sampling points is enough to provide an accurate depiction. Another common method is simulation of the transport processes of the contaminated liquid using advection-dispersion theory. However, if preferential flow paths are present in the geological formation, simulated behavior using advectiondispersion theory may not represent actual behavior (Zheng and Gorelick 2003). Simulations of the plume's density dis-

\footnotetext{
* Corresponding author

E-mail:wtbin@uch.edu.tw
}

tribution may underestimate the amount of contaminant that reaches the front of the plume, rapidly moving along preferential flow paths. A similar quandary is encountered during remediation of groundwater contamination sites, addressing whether the remediation reagent injected into the geological formation is transported effectively to a target position. Meeting the challenges posed by contaminants in complex geological environment and low-permeability strata have always been key issues in the remediation of groundwater contamination sites (Leeson et al. 2013). Therefore, how to depict the transport range of remediation reagents, similar to the depiction of contaminant distribution, is an important topic. Electrical resistivity tomography (ERT), a technique used in geophysical exploration, can be useful in resolving the issues encountered in treating groundwater contamination sites. ERT provides detailed images that can be used to deduce geological structure, contaminant distribution, and 
remediation reagent flow.

The underlying principle of ERT is based on direct current resistance. All observed data from the electrical potential of subterranean materials under the injection of an artificial electrical current are used to form an image of the electrical resistivity of the geological formation. This is measured by designating two current electrodes, and two additional electrodes for to recording the potential difference in potential electrodes. The use of automated multielectrode equipment allows rapid switching of electrode positions and distances. Finally, inversion of the data allows the resistivity or conductivity results to be depicted as contour maps. Because different materials have different electrical properties and the fluids in the pores of the material and the porosity of the material can affect observed resistivity values (based on Archie's law), the resistivity image can be used to resolve the subterranean environment (Barker 1981, 1989, 1992; Griffiths and Turnbull 1985; Griffiths et al. 1990; Griffiths and Barker 1993; Loke 1994; Zhou and Dahlin 2003; Dahlin and Zhou 2004; Loke et al. 2010a, b, 2013). With improvements in the equipment and computer technology during the past two decades, ERT surveys have become faster and more convenient in terms of field investigations and data processing. As ERT has the ability to produce high resolution images of formations at shallow depths, it is widely used in geology, archaeology, engineering, and environmental surveys (Bowling et al. 2007; Soupios et al. 2007a; Chang et al. 2012; Lin et al. 2013; Loke et al. 2013; Tong et al. 2013). Furthermore, ERT, undertaken in environmental contamination research such as investigations of landfills and groundwater contamination sites, can be used to clarify the scope and depth of landfills, investigate spills in contaminated areas, identify possible leakages, or assess the spatial distribution of contaminants (Atekwana et al. 2000; Halihan et al. 2005; Soupios et al. 2007b; Yang et al. 2008; Atekwana and Atekwana 2010; Martínez-Pagán et al. 2010; Vaudelet et al. 2011; Ayolabi et al. 2013; Wang et al. 2015). More specifically, cross-hole electrical resistivity tomography (CHERT) involves placing current and potential electrodes in boreholes. Inversion of the data is used to produce resistivity images of the geological formations between boreholes (Daily and Owen 1991; Shima 1992; Bing and Greenhalgh 1997; Zhou 1998; Sugimoto 1999). CHERT can be used to collect data from electrodes placed in two boreholes, or it can be used in conjunction with electrodes placed at ground surface to collect data between the ground surface and boreholes as well as data between boreholes (Petersen and al Hagrey 2009). When surface survey is not possible because of environmental limitations, CHERT is a feasible alternative that can provide a clearer interpretation of the geological data between boreholes (Deceuster et al. 2006). CHERT provides higher resolution than surface ERT in investigations of groundwater and groundwater contamination (Greenhalgh et al. 2000; Wilkinson et al.
2010). Because the electrodes can be permanently affixed in boreholes, CHERT is also an effective long-term monitoring system and has been used in recent years to monitor $\mathrm{CO}_{2}$ sequestration (Christensen et al. 2006; Al Hagrey 2011; Guo et al. 2011; Carrigan et al. 2013).

In this study, two case studies of the application of CHERT to contaminated groundwater remediation sites were examined. One involves a site where the groundwater was contaminated with light non-aqueous phase liquids (LNAPL). The source of contamination had been identified and remediation had begun. The objectives of this study in regard to the first site were periodic survey of the diffusion and distribution of the contaminants, leading to an indirect assessment of remediation efforts to assist with adjustments or corrections to the remediation plan. The other case study involves a site where the groundwater was contaminated with dense non-aqueous phase liquids (DNAPL) and the source of contamination had not been identified. The site covered an extensive area and the geological conditions were complex. As a result, the remediation process encountered a bottleneck. The remediation treatment involved evaluating the feasibility of a double-packer injection (DPI) method in combination with injecting reagents. The objective of the CHERT survey was to assess the affected area and transport time of the injected reagent. In both case studies, the positions of boreholes used in the CHERT survey were determined at the same time as the remediation plan. In addition to being used for geophysical surveys and monitoring, the boreholes could be used for groundwater sampling and hydraulic testing, reducing the cost and increasing the benefits from the boreholes. The equipment used in this study was the SuperSting R8 system manufactured by Advanced Geosciences, Inc. The resistivity data were inverted with the AGI EarthImager ${ }^{\odot} 2$-D software and EarthImager ${ }^{\odot}$ 3-D software (Advanced Geosciences, Inc. 2014), based on the finite element method and conjugate gradient inversion scheme (Yang 1999).

\section{NUMERICAL SIMULATION}

In CHERT surveys, the bipole-bipole electrode configuration, i.e., placing the two current electrodes in different boreholes, results in higher signal-to-noise ratio and higher electrical potential readings (Bing and Greenhalgh 2000). Placement of the current electrodes at different depths so that they are angled and not parallel can also increase observed data values (Goes and Meekes 2004). Based on the two studies, when factors such as measurement time and signal strength are considered, the configuration is designed to be employed in this study. The principle of the configuration is to locate both current electrodes and potential electrodes at various depths in two different wells. Consequently, the measured data can be obtained by the two pairs of electrodes in parallel and crossover configurations (see Figs. 3a and b 
in Bing and Greenhalgh 2000). Through the numerical simulation, the configuration can be evaluated and applied in the field experiments. Finite element forward modeling with a grid of half electrode interval and $1 \%$ random noise added in to the apparent resistivity, was used in the numerical simulation, and two-dimensional (2D) inversion was performed using a smoothness constrained method. The finite element method produces more accurate forward modeling solution than finite difference method with the same mesh discretization. Moreover, the finite element method models earth topography better. Details of the finite element calculation in our numerical simulation are described in Advanced Geosciences, Inc. (2014). The ability of ERT to depict the spatial distribution of groundwater contaminants or injected remediation reagents is predicated on a difference in resistivity between the intrusive materials and the geological background. When the resistivity of intrusive materials is 50 - 200\% of the resistivity of the geological setting, the distribution range can be depicted solely by the resistivity image (Fig. 1). However, when the resistivity of intrusive materials is similar to that of the geological background, causing the change in the formation resistivity to be very small, it may be more difficult to depict the distribution range solely by the resistivity image. In these instances, the time-lapse data processing method can assist in resolving the distribution of intrusive materials. Time-lapse data processing utilizes basic survey data and a base resistivity model. First, a base resistivity dataset is collected, so the base resistivity model of the site can be established as a reference model. The monitor survey is then repeated during monitoring using the same electrode configuration as the one used in the base survey. The algorithm does not reverse the monitor dataset separately but instead reverses the difference between the monitor and the underlying dataset. The result is expressed as the percentage difference in resistivity or conductivity through a contour map between the two parts. If the resistivity of intrusive materials is $25 \mathrm{ohm}-\mathrm{m}$ (Fig. 2a), and this value is $25 \%$ higher than the resistivity of the geological background, then the resistivity profile of intrusive materials is too similar to that of the background, and delineation of the contaminant distribution would be difficult (Figs. 2b and c). However, the distribution of intrusive materials can be depicted by the changes in resistivity (Fig. 2d). One constraint of this measurement method is that the resistivity of the background environment remains nearly constant. Frequent data collection at short interval is best suited to the depiction of changes in intrusive subterranean materials.

\section{CASE STUDIES}

\subsection{Case Study 1}

\subsubsection{Site 1 Background}

Site 1 is located in a chemical plant within a large in- dustrial zone, as shown by the yellow area in Fig. 3 while the gray areas depict plants of other companies. The site is located on a Holocene alluvium deposit and part of an alluvial plain approximately $1600 \mathrm{~m}$ from the coast. The alluvium deposit was over $100 \mathrm{~m}$ thick and composed primarily of clay, occasionally mixed with silt or fine sand. Under these geological conditions, the resistivity of the background geological materials should be low $(<20 \mathrm{ohm}-\mathrm{m})$. The groundwater table is found at a depth of approximately 2 - $3 \mathrm{~m}$ and generally flows northeast to southwest. Organic solvents, primarily benzene and diesel oil categorized as LNAPLs, were detected in the initial sampling of groundwater between the benzene storage tanks (the orange area in Fig. 3) and the processing area (the green area in Fig. 3). These contaminants are categorized as LNAPLs. The main product of this processing area was benzene, and diesel oil was used as an absorbent in the process. A large-scale examination of the groundwater, once every few years, was carried out revealing that the contamination was the result of leakage in the pipeline between the processing area and the storage tanks, although the time and volume of leakage were unknown. The source of contamination is shown by the red area in Fig. 3. Because this site is a working factory, stopping production was not feasible. Thus, when the leakage was discovered, large-scale excavation and removal were not performed, but rather the pipelines were replaced, and then remediation procedures targeting the subterranean contamination (e.g., oil skimming, injection of surfactants, and pump-and-treat) were initiated. Remediation had been underway for a period of time when high concentrations of benzene were detected at wells AW-1 and AW-2. These two wells were southeast of the assumed source of contamination. In other words, the LNAPLs were transported against the flow of the groundwater. This transport process was thought to be caused by pumping or local preferential flow paths that resulted in the diffusion of contaminants to the southeast. Because the storage tanks that were the source of contamination were located near the factory, transport of the contaminants beyond the factory borders would negatively affect the other companies in addition to causing environmental damage. Thus, remediation efforts were extended southward while continuing at the primary source of contamination. At this time, electrodes were placed in the new boreholes, designated AE-1 to AE-5, for CHERT surveying in addition to sampling and remediation.

Case Study 1 involved deducing the spatial distribution of contaminants from the CHERT results at three points in time, in conjunction with sample analysis. To establish the relative time relationship between each measurement, the time at which the first groundwater sampling was performed and benzene was detected at AW-1 and AW-2 was designated as Week 0. Subsequent groundwater samplings took place at Week 15, Week 68, and Week 123 (Table 1). The three CHERT surveys were performed at Week 12, Week 
(a)

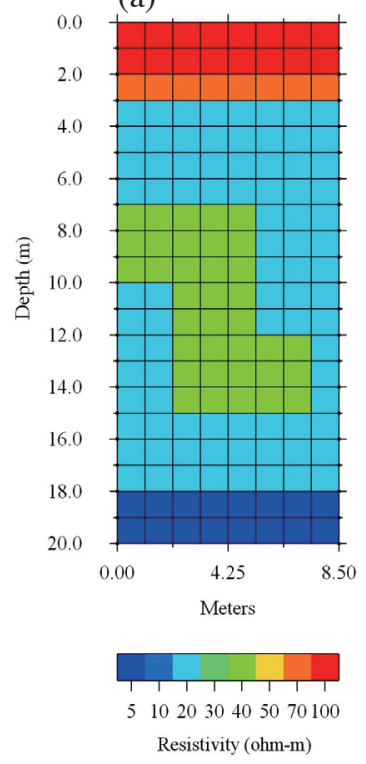

(b)

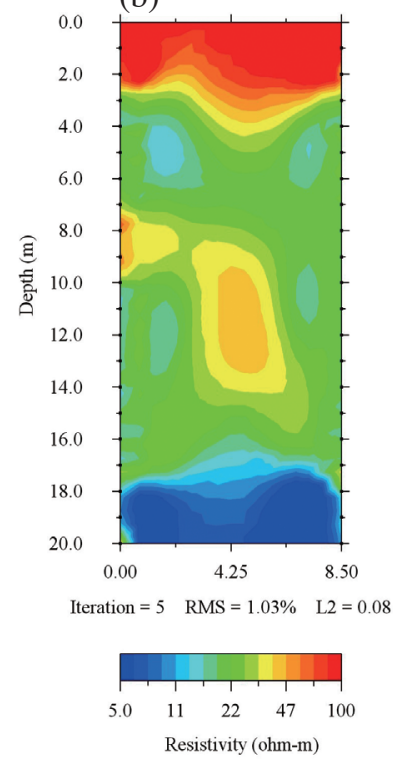

(c)

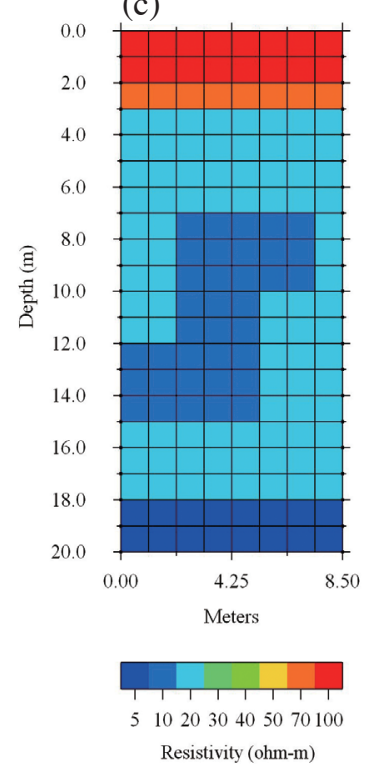

(d)

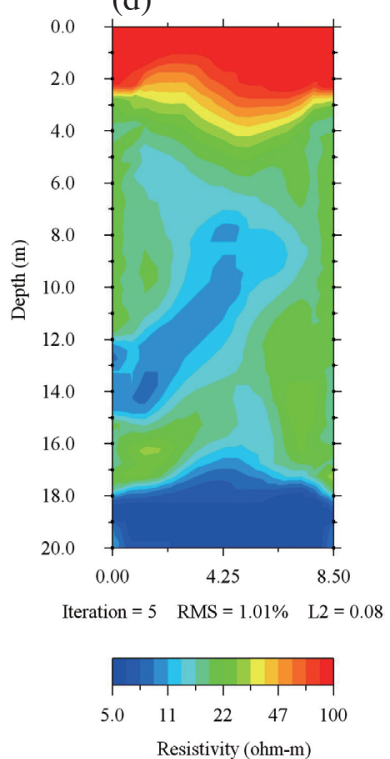

Fig. 1. Comparison of synthetic resistivity models and inverted models by simulation. The distance between two boreholes is $8.5 \mathrm{~m}$; the depth of each borehole is $20 \mathrm{~m} ; 20$ electrodes are in each borehole (1-20 m depth) with 1-m interval; and the number of data items are 1103 . According to the configuration, each electrode can be the current electrode or potential electrode. (a) Synthetic resistivity model with contaminant resistivity is twice the geological background resistivity. (b) Inverted model with contaminant resistivity is twice the geological background resistivity. (c) Synthetic resistivity model with contaminant resistivity is half of the geological background resistivity. (d) Inverted model with contaminant resistivity is half of the geological background resistivity.

(a)

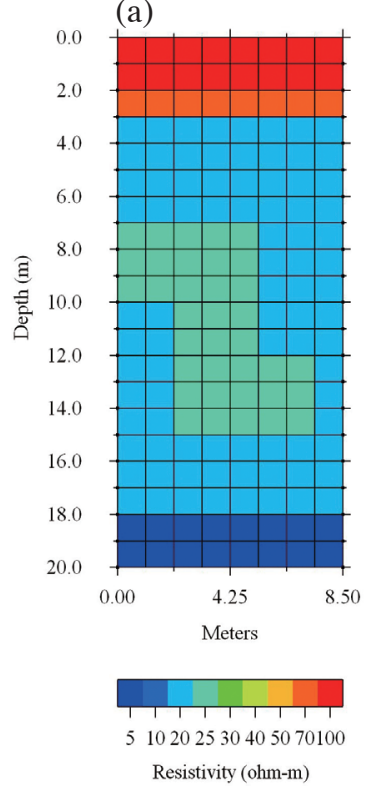

(b)

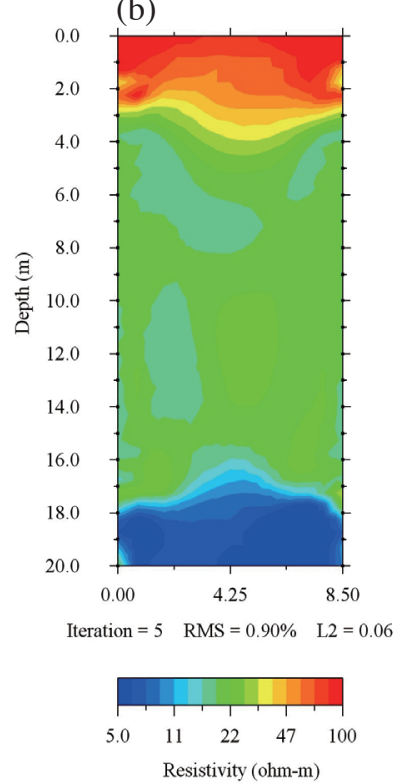

(c)
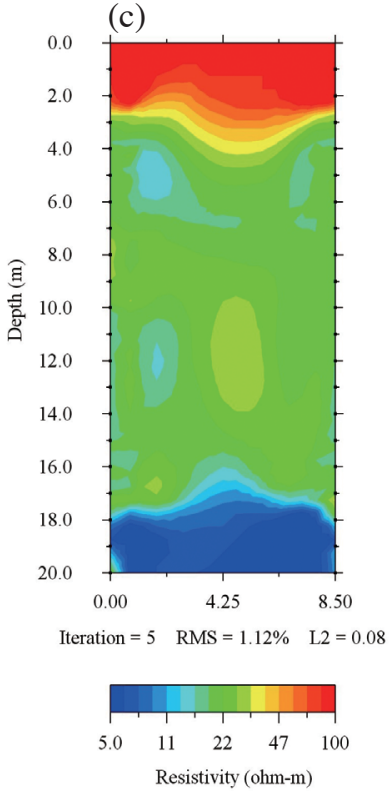

Percent Difference of Resistivity

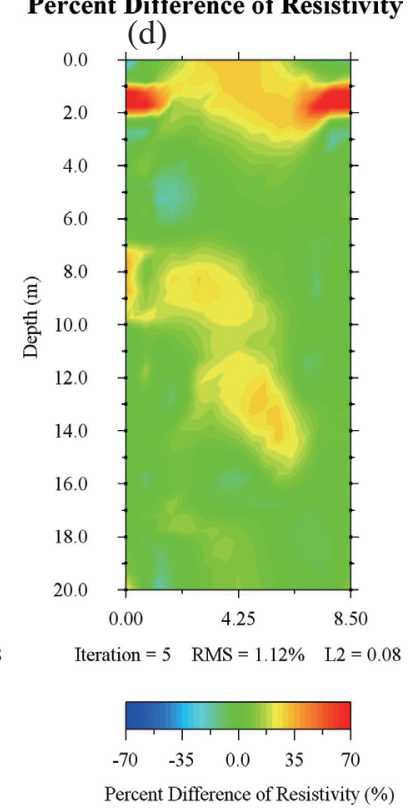

Fig. 2. Comparison of synthetic resistivity models and inverted models by simulation with the contaminant and geological background similar electrical resistivity. (a) The resistivity of the contaminant is $25 \mathrm{ohm}-\mathrm{m}$; the resistivity of the geological background is $20 \mathrm{ohm}-\mathrm{m}$. (b) Inverted model of the geological background without contaminant. (c) Inverted model with the contaminant. (d) Contour map of change in resistivity using time-lapse data processing. 


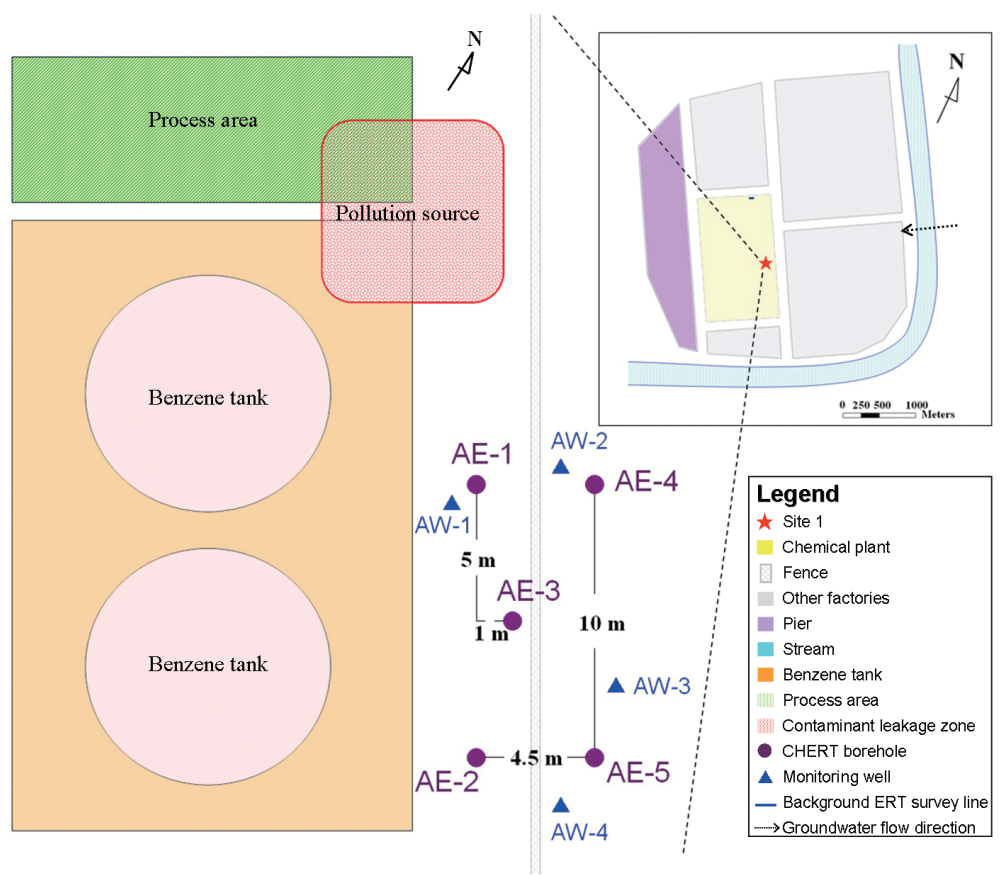

Fig. 3. Schematic diagram of Site 1.

Table 1. Benzene concentration at various time points. Samples were collected using bailers at a depth of $4 \mathrm{~m}$. Unit: $\mathrm{mg} \mathrm{L}^{-1}$.

\begin{tabular}{cccccc}
\hline Well & Time Point & $\begin{array}{c}\text { First } \\
\text { (Week 0) }\end{array}$ & $\begin{array}{c}\text { Second } \\
\text { (Week 15) }\end{array}$ & $\begin{array}{c}\text { Third } \\
\text { (Week 68) }\end{array}$ & $\begin{array}{c}\text { Fourth } \\
\text { (Week 123) }\end{array}$ \\
\hline & & 491 & 23.7 & 5.04 & 0.0005 \\
AW-1 & 25.9 & 36.8 & 17.9 & 12.6 \\
AW-2 & -- & 1.62 & 1.04 & 4.43 \\
AW-3 & -- & -- & -- & 2.41 \\
AW-4 & -- & 3.92 & 1.13 & 0.0537 \\
AE-2 & -- & 7.75 & 2.18 & 2.33 \\
AE-3 & -- & 1.65 & 0.0041 & 16.2 \\
AE-5 & & & & \\
\hline
\end{tabular}

66 , and Week 120. The survey area was $10 \mathrm{~m} \times 4.5 \mathrm{~m}$, and the relative locations of the boreholes are shown in Fig. 3. A total of 95 CHERT electrodes were placed in $0.5 \mathrm{~m}$ intervals at depths of 1 - $10 \mathrm{~m}$. Each survey combined eight cross-hole data profiles, AE-1 to AE-2, AE-1 to AE-3, AE-1 to AE-4, AE-2 to AE-3, AE-2 to AE-5, AE-3 to AE-4, AE-3 to AE-5, and AE-4 to AE-5. The total number of data items was 8248 , inverted with the EarthImager ${ }^{\odot} 3$-D software to obtain threedimensional (3D) images.

\subsubsection{Site 1 Results}

Using ERT to survey contaminant distribution requires understanding the electrical resistivity of the background geological materials and the contaminants. First, an ERT survey was conducted on uncontaminated land in the northwest sector of the factory (Fig. 4). Because the site's geographical composition was primarily sand and silt and the site was close to the coast, ERT results clearly showed that the resistivity of an uncontaminated saturated aquifer was approximately $12 \mathrm{ohm}-\mathrm{m}$ shown in blue in Fig. 4 . The primary contaminants at the site were benzene and diesel oil. The pure phase resistivity of these contaminants is approximately $10^{12}-10^{13} \mathrm{ohm}-\mathrm{m}$. During the initial recovery of LNAPLs, the solvents did not show signs of acidification. It can be assumed that the contaminants did not undergo substantial changes in properties, and the resistivities of the contaminants were higher than that of the geological background.

Remediation measures were taken immediately after a high concentration of benzene was detected at AW-1 via sample analysis. A surfactant was injected into AW-1, and 


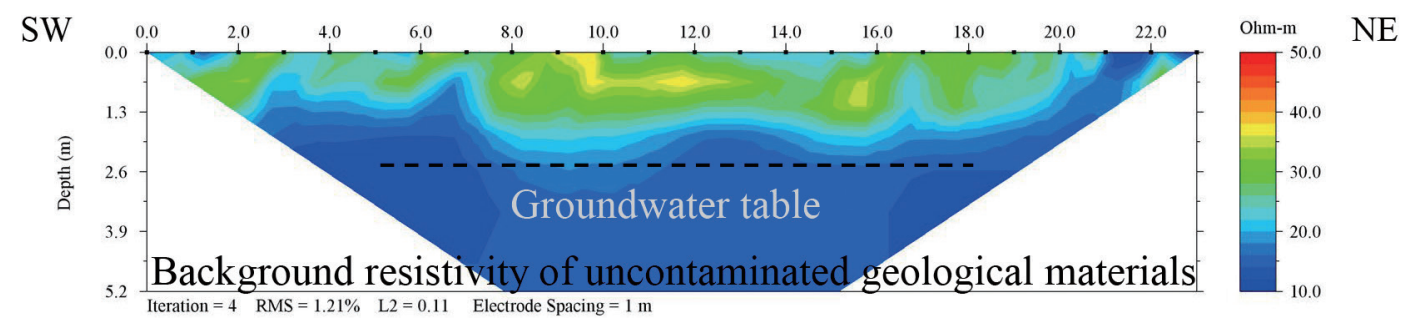

Fig. 4. Background resistivity values of Site 1. The ERT survey employed the Wenner-Schlumberger configuration. Electrode interval was $1 \mathrm{~m}$.

pump-and-treat remediation was initiated. In addition, new remediation and monitoring boreholes, designated AE-1 to AE-5, were drilled to the southeast for CHERT surveys, remediation procedures, and sampling. At the time of the first CHERT survey (Fig. 5), approximately two months of remediation measures had been completed at AW-1. Figure 5a shows the relatively low resistivity in the area around AE-1 (depicted in blue), which was assumed to be the result of continuous pump-and-treat remediation near borehole AW1. However, the area between AE-1, AE-3, and AE-4 showed higher resistivity ( $>20$ ohm-m; depicted in yellow to red). The AE-2 borehole to the south also showed higher resistivity. The spatial distribution of the contaminants can be inferred from the cross-sectional view of resistivity at a depth of $4 \mathrm{~m}$ (Fig. 5b). It was speculated that the contaminants had begun to migrate to the southeast. Based on the results of the CHERT survey, samples taken at the newly-drilled AW-3 borehole were analyzed. To obtain truer values of groundwater contaminant concentrations, remediation efforts were halted for two weeks prior to sample analysis at the boreholes. Results of the second sampling showed that although the benzene concentration at AW-1 decreased substantially, no improvement was seen at AW-2. At AW-3, AE-2, and AE-5, benzene was detected, albeit in low concentrations (Table 1, column 3). However, this indicated the spread of contaminants outside the boundaries of the factory, and results of the sample analysis verified the inferences made about contaminant distribution using the CHERT survey.

Remediation continued at the site for one year, and then the second CHERT survey was conducted (Fig. 6). Figure 6a shows the high resistivity area (depicted in yellow) had clearly expanded toward the southeast since the first CHERT survey. This result is consistent with the predictions from the first survey. Figure $6 \mathrm{~b}$ shows lower resistivity in the areas around the five boreholes. This was caused by a year of pump-and-treat remediation at AE-1 to AE-5. The resistivity in the areas around AE-2 and AE-3 was substantially lower in the second survey than in the first survey. Although the high resistivity area in the northwest sector persisted, overall, the high resistivity demonstrated by contaminants showed a decreasing trend. Although the contaminants still appeared to be migrating southeast, the contamination "seemed" to be confined to expected bound- aries as a result of remediation efforts and was no longer flowing outside the factory boundaries. Pump-and-treat remediation was again halted for two weeks prior to the third groundwater sample analysis, which showed that benzene concentration decreased in comparison to the second sample analysis (Table 1, column 4). Sample analysis and CHERT survey results mutually confirmed that the contaminant rebound effect was insignificant. Based on these results, the remediation team assumed that the spread of contamination was effectively under control.

After another year of remediation, the third CHERT survey was conducted (Fig. 7). Figure 7a shows a substantial increase in the high resistivity area in the southeast sector, compared to the second CHERT survey, and the peak resistivity position (depicted in red) had moved from the northwest sector to the southeast sector. Although Fig. 7b showed a relatively low resistivity near the five boreholes, the overall resistivity of the CHERT survey area clearly increased, particularly in the southeast sector. This indicated that the remediation techniques of continuous injection of surfactants and pump-and-treat failed to prevent the diffusion of contaminants. Possible reasons for the failure included: (1) Remediation of the site was limited by the continued operation of the large factory, and large-scale excavation of the source of contamination was not feasible; (2) Differences in permeability in localized areas of fine-grain geological materials may have prevented the effective distribution of surfactant throughout the entire geological formation; and (3) Differences in the hydraulic conductivity of geological materials can cause asymmetry in a pump's radius of influence, leading to greater difficulty in predicting the transport of contaminants. The fourth sample analysis, conducted after pump-and-treat remediation was halted, showed a substantial increase in benzene concentrations at AW-3 and AE-4 and relatively high benzene concentration at AW-2 (Table 1, column 5). Based on the CHERT survey results, remediation efforts to contain the spread of contaminants were suspected to have failed, and contaminants were suspected to have migrated southeast. Thus, it was suggested that the remediation team drill a new borehole, designated AW-4, southeast of the survey field. Benzene was detected in samples from this well. CHERT and sample analysis results both showed that the contamination at this site had not 
(a)

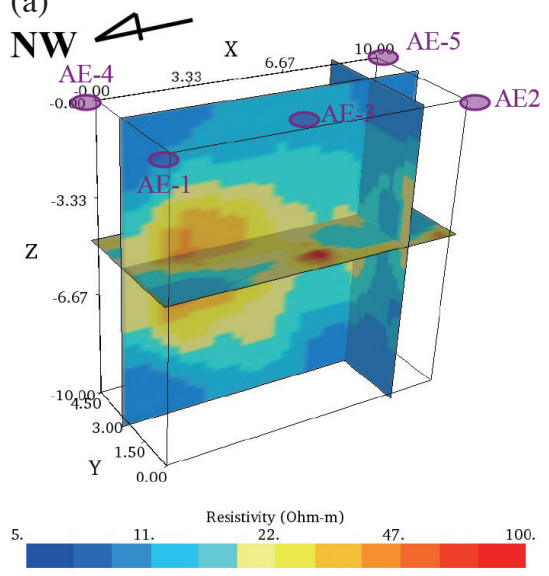

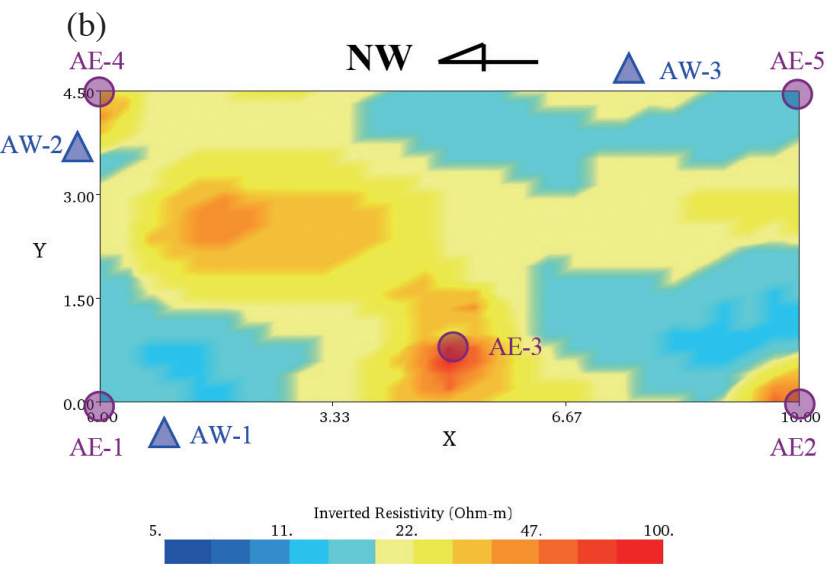

Fig. 5. Results of first CHERT survey (Week 12). (a) 3D fence diagram; (b) cross-sectional view at a depth of $4 \mathrm{~m}$.
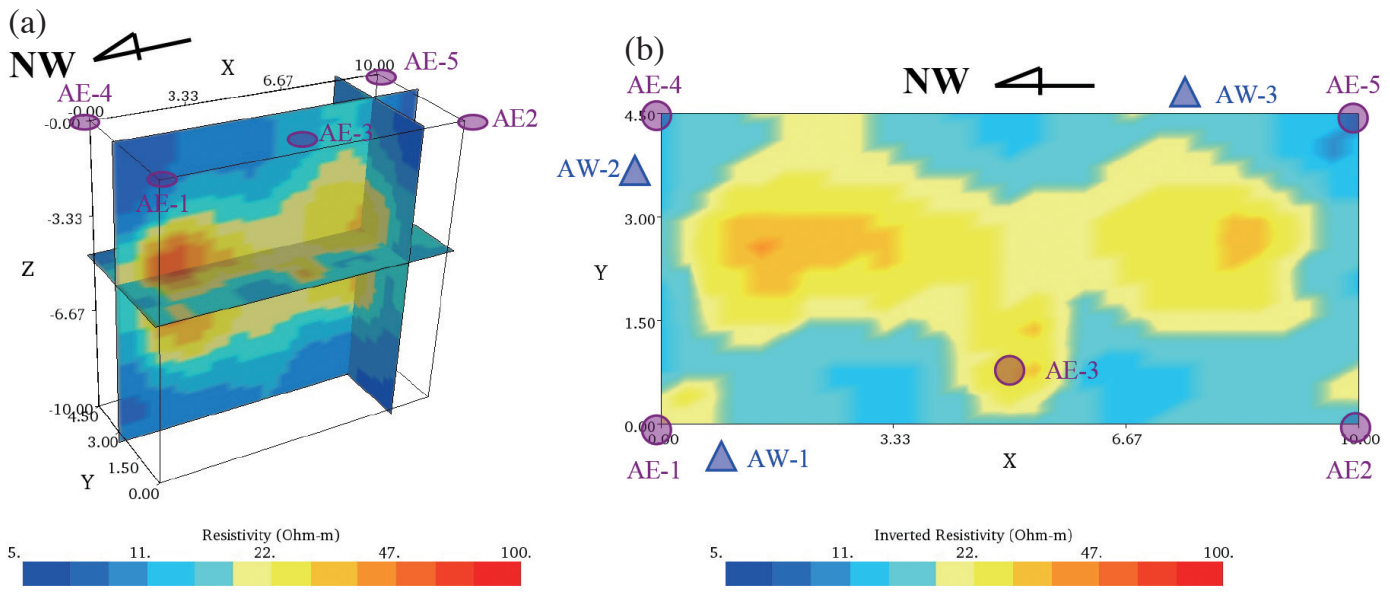

Fig. 6. Results of second CHERT survey (Week 66). (a) 3D fence diagram; (b) cross-sectional view at a depth of $4 \mathrm{~m}$.
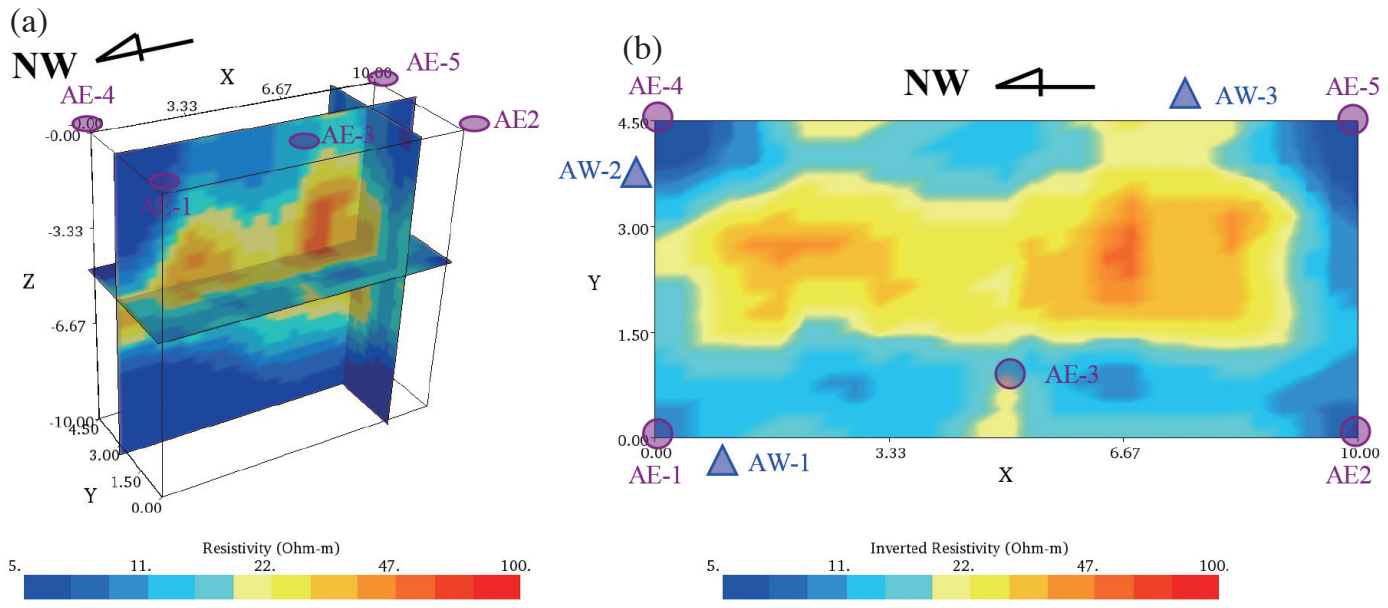

Fig. 7. Results of third CHERT survey (Week 120). (a) 3D fence diagram; (b) cross-sectional view at a depth of $4 \mathrm{~m}$. 
been contained as predicted; instead, it had spread outside the factory borders. Overall remediation efforts should be re-evaluated and more aggressive in the southeast sector.

\subsection{Case Study 2}

\subsubsection{Site 2 Background}

Site 2 is located outside a petrochemical industrial zone, above the downstream section of a groundwater flow (Fig. 8). The industrial zone was established over 40 years ago and contains numerous large-scale, continuously operating chemical plants. In 1996, contaminants such as vinyl chloride (VC), 1,1-dichloroethene (1,1 DCE), trichloroethylene (TCE), tetrachloroethene (PCE), and 1,2-dichloroethane (1,2 DCA) were detected at many of the monitoring wells distributed throughout factories in the industrial zone. The various factories with contamination issues began groundwater remediation treatment at varying times (the earliest treatment began over 10 years ago), and remediation efforts continue today. In the past, the waste water might have been dumped underground or injected into the groundwater because of a lack of environmental awareness and knowledge. Furthermore, many factories have changed owners or industries, making it impossible to establish the exact history or source of contamination. The Environmental Protection Agency has treated the entire industrial zone as one source of contamination (depicted in gray in Fig. 8), and the primary goal of remediation has been to prevent the diffusion of contamination outside the zone. However, in 2009 , contaminants were detected in the groundwater outside the industrial zone in an area that had been developed into a residential zone. Because of the dangers to humans posed by contaminated water, remediation efforts began in 2010 in the contaminated area outside the industrial zone; however, the efforts yielded lackluster results. Remediation efforts at this site face two difficult problems: the contamination has reached a depth of $30 \mathrm{~m}$, and the background geological materials make it difficult to predict the direction of transport of remediation reagents.

The site is located on a Holocene alluvium deposit approximately $50 \mathrm{~m}$ thick, and contains gravel, sand, silt, and clay. The composition between $1-15 \mathrm{~m}$ is primarily sand and gravel, occasionally mixed with silt. The hydraulic conductivity is high and the material is relatively homogenous, thus, the transport of reagents could be manipulated via conventional remediation techniques such as injection of reagents and pump-and-treat. The composition between 16 - $35 \mathrm{~m}$ was primarily sand, silt, and clay with low hydraulic conductivity. The clay constitutes a greater proportion at these depths and is unevenly distributed or discontinued. As a result, the groundwater flow more complicated. This geological formation behaves like an aquitard and the transport of remediation reagents is difficult to predict or ensure efficient transmission in silt and clay layers. Furthermore, when bioremediation reagents are used, they can form a biofilm in the area around the remediation borehole over time if they are not distributed effectively. When this happens, conventional reagent injection techniques, which rely on gravity, will cause the reagent to overflow from the mouth of the borehole, and become ineffective as a remediation technique.

Because of this, the remediation team designed a set of remediation procedures based on DPI technology and the EcoClean reagent, a biostimulation reagent with a Japanese patent from EcoCycle Corporation, in the hopes of

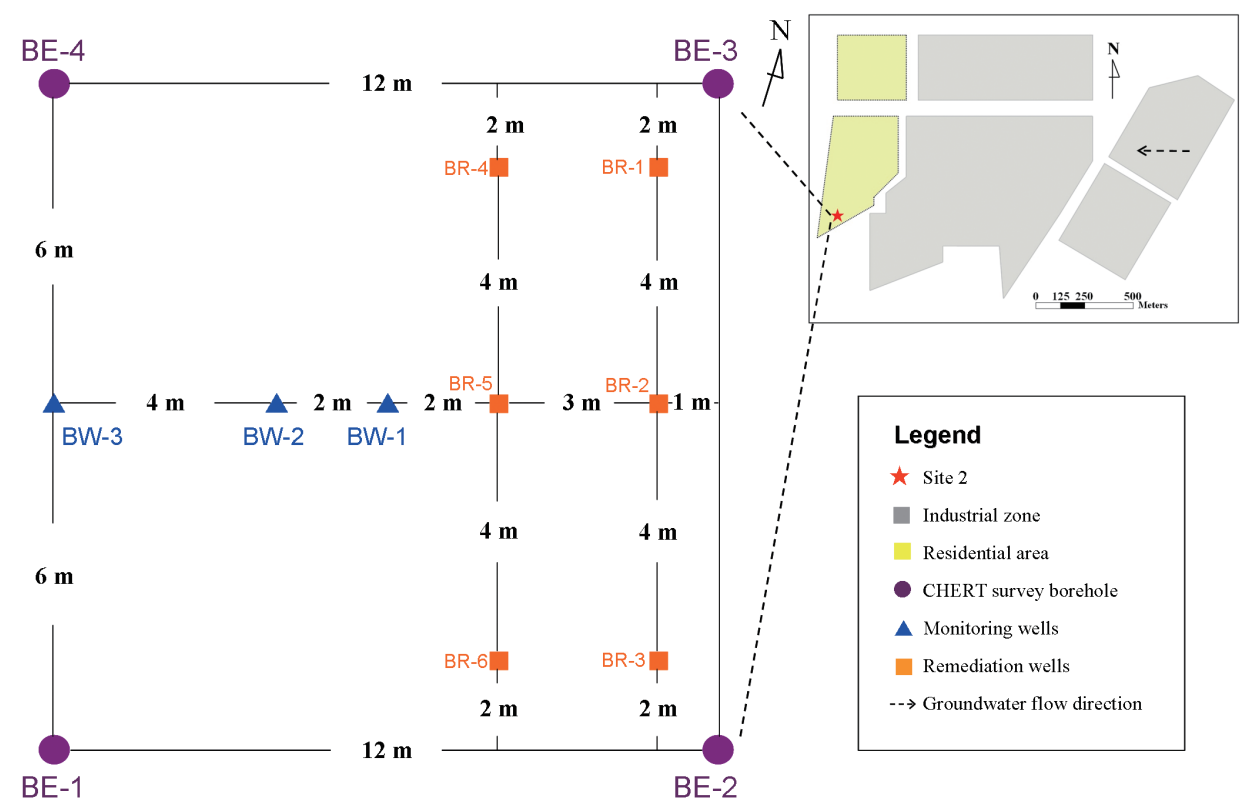

Fig. 8. Schematic diagram of Site 2. 
resolving this complex groundwater contamination problem. The primary objective of Case Study 2 was to use CHERT surveys to assess the transport pathways and area of affect of the reagent, delivered via the DPI method, in a geological formation with low permeability. A $12 \mathrm{~m} \times 12 \mathrm{~m}$ borehole survey field was established in an area known to be contaminated outside the industrial zone. In the survey field, VC contamination was detected at a depth of 19-29 m in a sample obtained from the first monitoring well that was drilled (BW-2). Subsequently, VC contamination was also found at wells BW-1 and BW-3, which were positioned upstream and downstream, respectively, of BW-2. Boreholes BR-1 to BR-6 were positioned upstream from the three monitoring wells for injection of remediation reagents. The purpose of this placement was to examine whether pressurized injection of reagents can effectively transport the reagents downstream in an aquitard, leading to the ultimate goal of VC concentration reduction and remediation of the contaminated groundwater. Four CHERT boreholes (designated BE-1 to BE-4) were positioned surrounding the monitoring and injection boreholes. These four boreholes were also used for monitoring the groundwater. A total of 80 CHERT electrodes were placed in $1 \mathrm{~m}$ intervals at depths of 16 - $35 \mathrm{~m}$. Each survey collected four elements of 2D crosshole data, including BE-1 to BE-2, BE-2 to BE-3, BE-3 to BE-4, and BE-1 to BE-4. A total of 1103 individual 2D profile data items were inverted with the EarthImager ${ }^{(} 2-\mathrm{D}$ software to obtain 2D images. The configuration of all boreholes is shown in Fig. 8 and the analysis of the geological composition is shown in Table 2. Table 3 shows data from groundwater sampling at the boreholes at various depths prior to remediation. Results showed contamination in the aquitard at BE-1 to BE-4, in addition to BW-1 to BW-3.

\subsubsection{Site 2 Results}

Before the remediation reagent injection, a CHERT survey was carried out and the data was used as background monitoring values. Reagent injection was performed over a period of four days. On the first and second day, the reagent was injected into BR-1, BR-2, and BR-3 at depths of 18 , $20,22,24,26,28$, and $30 \mathrm{~m}$. At each depth, $500 \mathrm{~L}$ of the reagent was injected. Immediately after reagent injection, a CHERT survey was performed and four profiles were obtained. On the third and fourth day, the process was repeated at boreholes BR-4, BR-5, and BR-6. A CHERT survey to obtain four profiles was performed immediately after its completion. A last CHERT survey to obtain four profiles was performed on the fifth day. The point in time at which the reagent injection began at BR-1, BR-2, and BR-3 was designated as Hour 0 . Thus, the first CHERT survey after remediation began was performed at Hour 36; injection of agents into BR-4, BR-5, and BR-6 began at Hour 48; the second CHERT survey after remediation began was performed at Hour 82; and the third CHERT survey after remediation began was performed at Hour 96. The electrical conductivity of the groundwater in the aquitard prior to reagent injection was approximately $1000-1500 \mu \mathrm{S} \mathrm{cm}^{-1}$ and the conductivity

Table 2. Analysis of geological materials at Site 2 .

\begin{tabular}{c|ccc|c|c}
\hline \multirow{2}{*}{ Depth (m) } & \multicolumn{2}{|c|}{ Material Particle Size Analysis (\%) } & Type of Material & $\begin{array}{c}\text { Hydraulic Conductivity } \\
\left(\mathbf{c m ~ s}^{-1}\right)\end{array}$ \\
\cline { 2 - 4 } & Sand & Silt & Clay & & $3.5 \times 10^{-5}$ \\
$16-18$ & 4 & 44 & 52 & Silty Clay & $3.2 \times 10^{-3}$ \\
$18-20$ & 75 & 20 & 5 & Silty Sand & $3.3 \times 10^{-2}$ \\
$20-25$ & 98 & 2 & 0 & Sand & $8.4 \times 10^{-5}$ \\
$25-26$ & 36 & 57 & 7 & Sandy Silt & $7.7 \times 10^{-5}$ \\
$26-30$ & 18 & 60 & 22 & Clayey Silt & $3.4 \times 10^{-4}$ \\
$30-34$ & 62 & 36 & 2 & Silty Sand & \\
\hline
\end{tabular}

Table 3. Pre-remediation VC concentrations at Site $2\left(\mathrm{mg} \mathrm{L}^{-1}\right)$.

\begin{tabular}{|c|c|c|c|c|c|c|c|}
\hline $\begin{array}{ll} & \text { Borehole } \\
\text { Depth }(\mathrm{m}) & \end{array}$ & BW-1 & BW-2 & BW-3 & BE-1 & BE-2 & BE-3 & BE-4 \\
\hline 19 & 0.319 & 8.631 & 0.896 & 0.112 & 0.990 & 0.029 & 0.515 \\
\hline 21 & 0.376 & 9.841 & 0.978 & 0.100 & 1.464 & 0.028 & 4.443 \\
\hline 23 & 0.521 & 9.267 & 3.494 & 0.245 & 1.373 & 0.027 & 7.571 \\
\hline 25 & 0.570 & 14.341 & 2.368 & 0.319 & 6.701 & 0.968 & 11.366 \\
\hline 27 & 0.470 & 15.839 & 5.658 & 0.331 & 13.363 & 0.311 & 7.436 \\
\hline 29 & 0.510 & 15.391 & 6.891 & 0.337 & 12.507 & 0.118 & 15.170 \\
\hline
\end{tabular}


of the reagent was $8580 \mu \mathrm{S} \mathrm{cm}$. Thus, conductivity of the geological formations after reagent injection was expected to increase (resistivity would decrease). These changes in electrical properties, detected by ERT, can be used to deduce the reagent's transport pathways and area of effect. After the reagent injection processes were completed, water samples were obtained from each borehole at various depths to directly verify results of the remediation efforts.

The eight CHERT survey profiles of background and at Hour 36 are shown in Fig. 9. The resistivity profiles showed slight changes in the electrical properties of the geological formation after reagent injection, such as the slight changes near BR-1 to BR-3 as seen in the BE-2 to BE-3 profile. However, these changes were not significant enough to deduce the primary transport path of the reagents. Therefore, timelapse method was applied, using changes in conductivity to depict electrical property differences after the first reagent injection (Fig. 10). Because the electrical conductivity of the reagent was substantially higher than that of the original groundwater, areas that showed an increase in conductivity could be inferred to be the primary transport path of the reagent. Results showed that the sand layer at a depth of 20 - $25 \mathrm{~m}$ exhibited the highest increase in conductivity, with clear pattern in all four directions after reagents were injected at BR-1 to BR-3. The BE-1 to BE-4 profile (Fig. 10d), which depicts the area furthest downstream, showed a $20 \%$ increase in conductivity in the sand layer. This indicates that DPI of reagents resulted in effective transport of the reagent: the reagent travelled at least $10 \mathrm{~m}$ in $36 \mathrm{~h}$. In the aquitard, the most apparent change was observed in the BE-2 to BE-3 profile (Fig. 10b). The BR-1 to BR-3 boreholes were located approximately $1 \mathrm{~m}$ downstream from the area depicted in the BE- 2 to BE- 3 profile. The DPI of reagents caused the reagent to travel a distance of $1 \mathrm{~m}$ in the aquitard, against the groundwater flow. The BE-3 to BE-4 profile showed a slight increase in the conductivity of the aquitard. Thus, the reagent also traveled northward. In contrast, the conductivity of the aquitard showed no substantial changes in the BE-1 to $\mathrm{BE}-2$ profile. Thus, it could be inferred that within the experimental field, conditions to the north were more conducive to reagent transport than were conditions to the south.

After 82 hours, reagent injection was completed at boreholes BR-4 to BR-6. Results of the CHERT survey showing changes in conductivity relative to background values are shown in Fig. 11. Because BR-4 to BR-6 were located further downstream, changes in the conductivity of the sand stratum were even more apparent. Results at Hour 82 showed clear increases in conductivity of the aquitard in the BE-2 to BE-3 and BE-3 to BE-4 profiles, but changes in the conductivity of the aquitard at a depth of $26-30 \mathrm{~m}$ were not apparent in the BE-1 to BE-2 and BE-1 to BE-4 profiles. Conductivity increased in areas around the BE-1 to BE-4 boreholes, indicating that the reagent had traveled to these boreholes and showed signs of accumulation.
The remediation reagent was a milky white bioremediation agent. Samples obtained from boreholes BW-1 to BW-3 and BE-1 to BE-4 were turbid and had a foul odor. However, the water sample from any single borehole contains a mixture of water from all depths. Thus, these changes to the water samples did not indicate that the reagent was present at all depths. Furthermore, reagent transport may not follow ideal, straight paths; their transport is primarily decided by preferential flow paths.

Figure 12 shows the results of CHERT survey conducted at Hour 96, displaying changes in conductivity relative to background values. Figure 12a shows that the BE-1 to BE-2 profile depicted a slight increase in the conductivity of the aquitard, which indicated that the reagent was effectively transported southward. The only area where conductivity did not change throughout the experiment is outlined in red (at a distance of $6 \mathrm{~m}$ and a depth of $28-30 \mathrm{~m}$ ) in the BE-1 to BE-4 profile (Fig. 12e). This is the location of BW3 , and it can be inferred from these results that the reagent never reached a depth of $28-30 \mathrm{~m}$ at BW-3. A possible reason is that the geological formation at this location has a high proportion of clay and is less permeable. In addition, this location is $8 \mathrm{~m}$ away from the injection boreholes, and this distance may not be reachable even by DPI of reagent. Table 4 shows the groundwater sample analysis data after remediation. Analysis of these results shows that VC was not detected at BW-1, which was located closest to the injection boreholes. VC concentration at BW-2 decreased significantly at all depths. This same trend was seen in BW3 , but the VC concentration was $5.687 \mathrm{mg} \mathrm{L}^{-1}$ at a depth of $29 \mathrm{~m}$. This indicates that the reagent did not reach this depth and verifies inferences made based on the CHERT survey. $\mathrm{VC}$ concentration also decreased in BE- 1 to BE-4, with the highest decrease seen at BE-3. CHERT survey results also show that the highest conductivity among BE-1 to BE-4 was seen near BE-3, indicating that the reagent had accumulated near this borehole. Although $\mathrm{VC}$ concentration decreased at $\mathrm{BE}-2$, it was still relatively high. A possible reason is that BE-2 was located upstream of the injection boreholes. Another possible reason is inferred by the CHERT results; that the distribution of materials in the aquitard made it more likely for the reagent to travel northward. Based on these results, future remediation efforts should focus on BE-2 and BW-3, especially at the depth of $29 \mathrm{~m}$ of BW-3.

\section{DISCUSSION}

In Case Study 1, CHERT surveys were used to assist in deducing the transport direction of the LNAPL, and this information could assist the remediation team in making adjustments or corrections to the remediation process. At Site 1 , the nature and location of the source of contamination had been confirmed, the contaminant was still in the pure phase, and the resistivity of the contaminant was substantially 

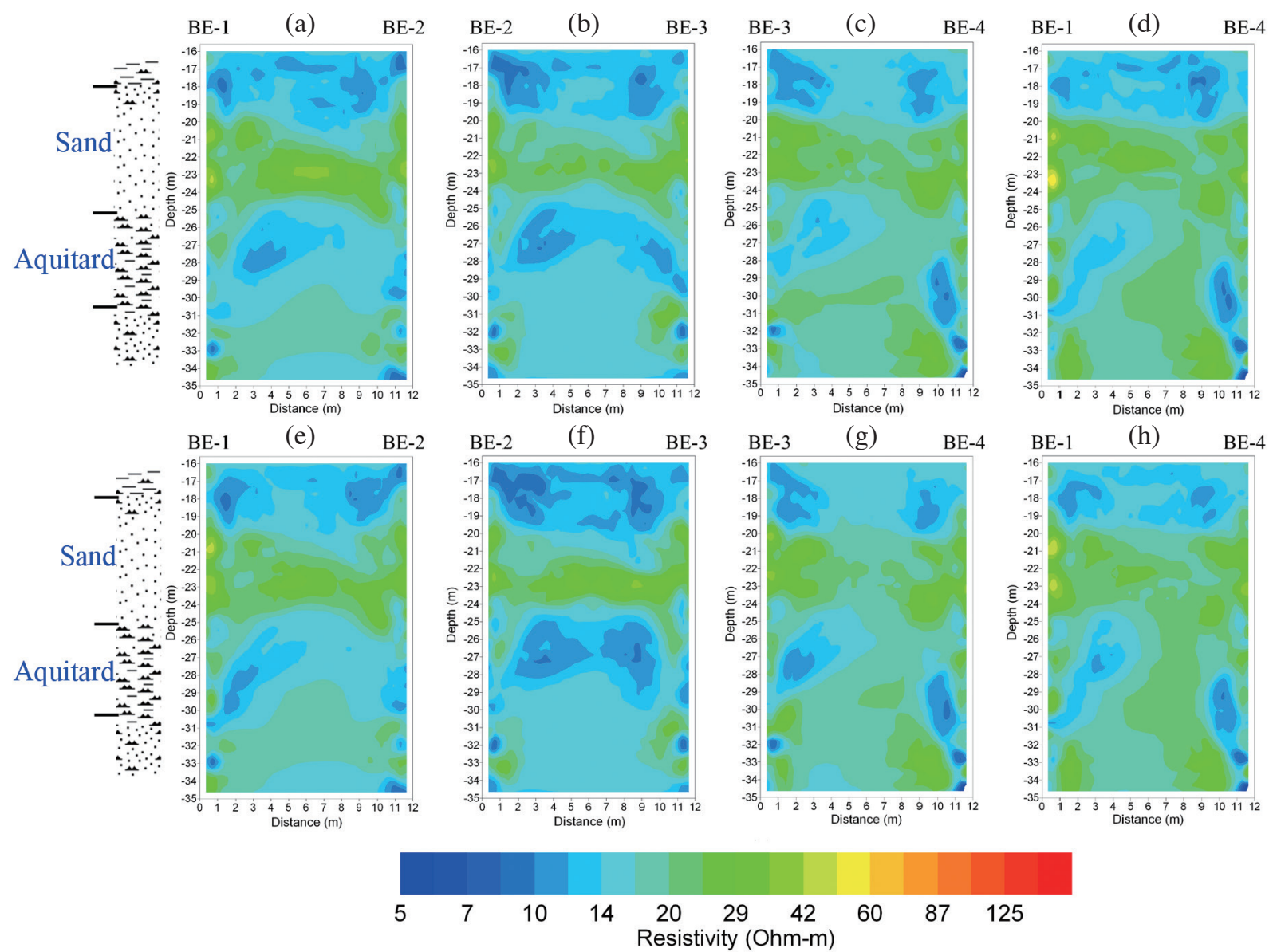

Fig. 9. Result of CHERT surveys. Geological sections based on the borehole observation is added to the left side of the tomography. (a) BE-1 to BE-2 background profile. (b) BE-2 to BE-3 background profile. (c) BE-3 to BE-4 background profile. (d) BE-1 to BE-4 background profile. (e) BE-1 to BE-2 profile after $36 \mathrm{~h}$. (f) BE-2 to BE-3 profile after $36 \mathrm{~h}$. (g) BE-3 to BE-4 profile after $36 \mathrm{~h}$. (h) BE-1 to BE-4 profile after $36 \mathrm{~h}$.

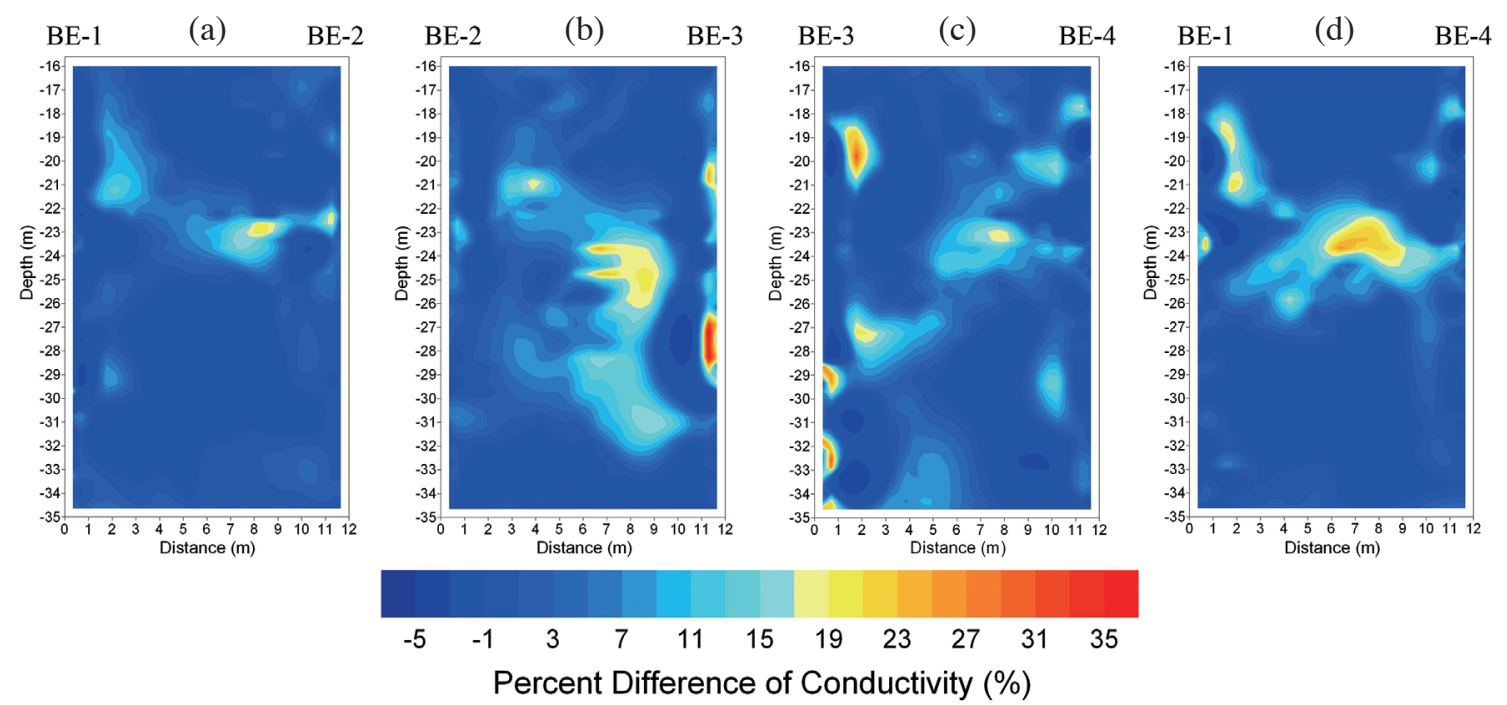

Fig. 10. Changes in electrical conductivity $36 \mathrm{~h}$ after reagent injection from CHERT surveys. (a) BE-1 to BE-2 profile. (b) BE-2 to BE-3 profile. (c) BE-3 to BE-4 profile. (d) BE-1 to BE-4 profile. 

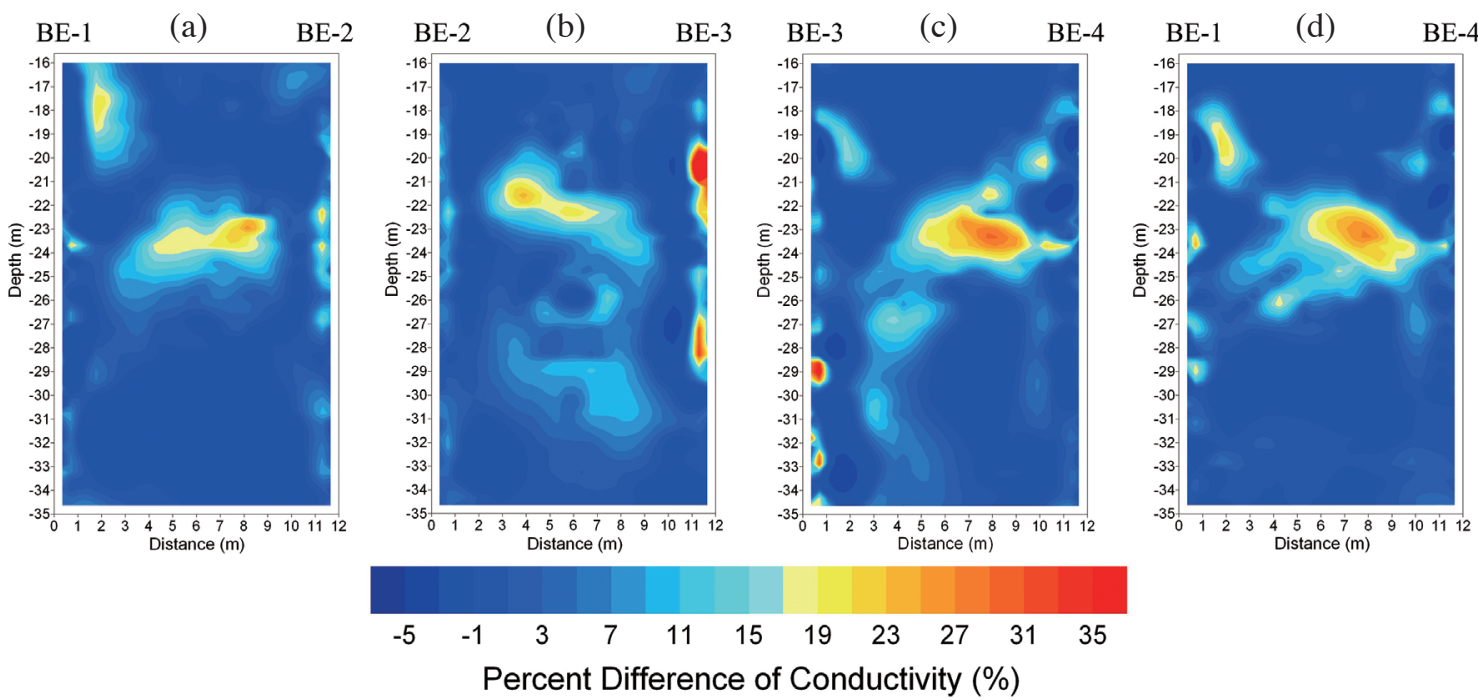

Fig. 11. Changes in electrical conductivity $82 \mathrm{~h}$ after reagent injection from CHERT surveys. (a) BE-1 to BE-2 profile. (b) BE-2 to BE-3 profile. (c) BE-3 to BE-4 profile. (d) BE-1 to BE-4 profile.
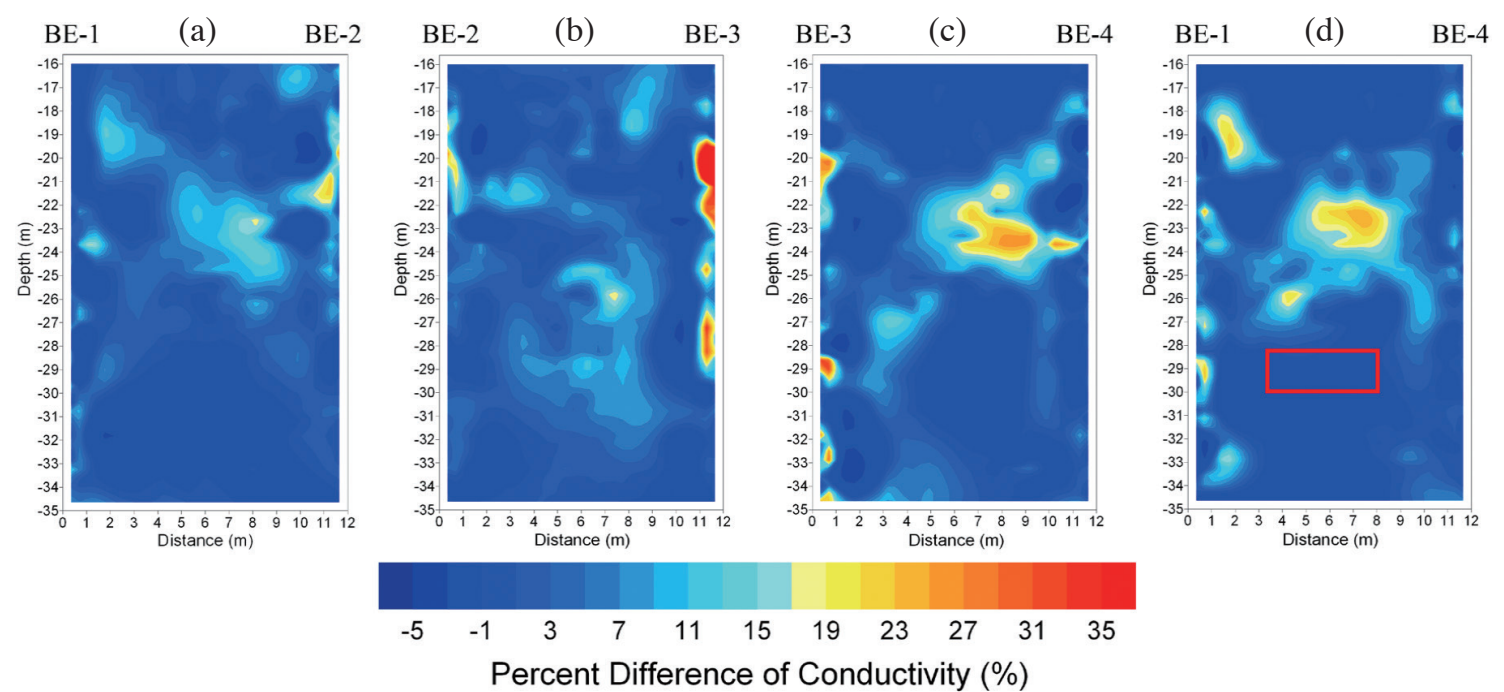

Fig. 12. Changes in electrical conductivity $96 \mathrm{~h}$ after reagent injection from CHERT surveys. (a) BE-1 to BE-2 profile. (b) BE-2 to BE-3 profile. (c) BE-3 to BE-4 profile. (d) BE-1 to BE-4 profile.

Table 4. Post-remediation VC concentrations $\left(\mathrm{mg} \mathrm{L}^{-1}\right)$.

\begin{tabular}{|c|c|c|c|c|c|c|c|}
\hline Depth (m) Borehole & BW-1 & BW-2 & BW-3 & BE-1 & BE-2 & BE-3 & BE-4 \\
\hline 19 & N/D & 0.033 & 0.416 & 0.007 & 0.582 & $\mathrm{~N} / \mathrm{D}$ & 0.061 \\
\hline 21 & $\mathrm{~N} / \mathrm{D}$ & 0.034 & 0.467 & 0.025 & 0.545 & $\mathrm{~N} / \mathrm{D}$ & 0.176 \\
\hline 23 & N/D & 0.039 & 0.490 & 0.053 & 0.535 & 0.004 & 0.269 \\
\hline 25 & $\mathrm{~N} / \mathrm{D}$ & 0.040 & 0.567 & 0.061 & 1.362 & 0.007 & 0.421 \\
\hline 27 & N/D & 0.040 & 0.717 & 0.066 & 1.256 & 0.012 & 0.028 \\
\hline 29 & $\mathrm{~N} / \mathrm{D}$ & 0.041 & 5.687 & 0.067 & 1.308 & 0.010 & 0.036 \\
\hline
\end{tabular}


higher than that of the background geological material. Thus, resistivity profiles could be used directly to depict changes to the contaminant. However, in Case Study 2, the resistivity profile could only be used to deduce the distribution of geological materials and not the distribution of the contaminants. This was because contamination at Site 2 had begun decades ago, and it was possible that all the groundwater at the site had been contaminated by the contaminated factory waste water. This is also why the groundwater at the site showed relatively high conductivity. In addition, the main contaminant just outside of the industrial zone was $\mathrm{VC}$, and $\mathrm{VC}$ is highly soluble in water. This differs from the situation at Site 1, where the contaminant was still in its pure phase and was not water-soluble. Trace amounts of $\mathrm{VC}$ in the groundwater would not necessarily cause a significant change in the groundwater's electrical properties. Thus, the resistivity profile could not be used to determine the extent of contamination in the stratum. In Case Study 2, the conductivity of the injected reagent was approximately 5 - 8 times that of the groundwater, but it was still difficult to delineate the spatial distribution of the reagent through the resistivity profile alone. This is because the main component of the resistivity profile was geological material, and even a high conductivity reagent like that injected into the layer in this case study was not enough to substantially change the distribution of resistivity in the overall setting. However, by using a time-lapse data processing method and subtracting the values of the background geological material, the changes in conductivity could clearly indicate the transport and area of effect of the reagent.

The concept of periodic monitoring was applied to both case studies. The interval used in Case Study 1 was carried out once a year and some groundwater contaminated remediations were undertaken. Therefore, it is unable to offer or produce a timely warning when the spread of contaminants was discovered. The surveys in Case Study 2 were conducted at short intervals, every another day. Thus, minor changes could be detected through time-lapse data processing methods to propose suggestions for follow-up remediation work. Both case studies show that if the CHERT equipment can be installed simultaneously as the monitoring and remediation wells, more $2 \mathrm{D}$ or $3 \mathrm{D}$ data can be obtained regarding the contamination site. With short survey intervals, four-dimensional (4D) or even approximate real-time data could be obtained. This would also increase the practical value of the wells. The wells could be used for more than obtaining groundwater samples; they could be used for geophysical surveys. Particularly in complex contamination sites, the transport of contaminants or remediation agents may not align with the general flow of the groundwater. CHERT surveys can assist in identifying localized preferential flow paths. Use of this technique requires an understanding of the hydrogeology, contamination history, and nature of contamination of the site. Because CHERT results are presented as resistivity data, the physical properties of the target material and any possible reactions with the geological material must be examined to determine if the material can produce a sufficient difference in electrical properties to be discernable in a CHERT survey.

\section{CONCLUSION}

Examination of these two case studies showed that CHERT surveys can be useful in the investigation of groundwater contamination sites and evaluation of remediation efforts, as well as the determination of the transport direction and localized preferential flow paths. If the CHERT equipment is installed when the boreholes are drilled, the boreholes can be used for long-term collection of geophysical data as well as sampling and remediation. The wells would then be more economical from the enhanced benefits. When the target material and the background geological material are clearly distinct, the resistivity image can delineate the transport and spatial distribution of the contaminant. When the target material and the background geological material are relatively similar, the differences in electrical properties can still be used to depict the position of the invasive materials through application of time-lapse methodology. In largescale or complex contamination sites, CHERT surveys can provide more information than conventional environmental engineering methods. Sample analysis results are limited to one dimension, but CHERT surveys can provide $2 \mathrm{D}, 3 \mathrm{D}$, or even 4D data. If time-lapse methodology is used to reduce the intervals between surveys, the data would be more complete and useful, as the data would approximate real-time monitoring. Integration of ERT into the field of environmental engineering can substantially improve the overall effectiveness of surveying or remediation in the monitoring or long-term groundwater management of contamination sites.

Acknowledgements We would like to thank Soil and Groundwater Pollution Remediation Fund Management Board for the support of this study. This study was funded under grant EPA-106-GA12-02-A255 of the Environmental Protection Administration, Executive Yuan, R.O.C. We also thank Manager R. H. Chen and Manager S. T. Lin of FGC Co., Ltd. Taiwan for DPI technical support.

\section{REFERENCES}

Advanced Geosciences, Inc., 2014: Instruction Manual for EarthImager 2D, Version 2.4.2, Resistivity and IP Inversion Software, Austin, Texas.

Al Hagrey, S. A., 2011: $\mathrm{CO}_{2}$ plume modeling in deep saline reservoirs by 2D ERT in boreholes. The Leading Edge, 30, 24-33, doi: 10.1190/1.3535429. [Link]

Atekwana, E. A. and E. A. Atekwana, 2010: Geophysical signatures of microbial activity at hydrocarbon 
contaminated sites: A review. Surv. Geophys., 31, 247283, doi: 10.1007/s10712-009-9089-8. [Link]

Atekwana, E. A., W. A. Sauck, and D. D. Werkema, 2000: Investigations of geoelectrical signatures at a hydrocarbon contaminated site. J. Appl. Geophys., 44, 167180, doi: 10.1016/S0926-9851(98)00033-0. [Link]

Ayolabi, E. A., A. F. Folorunso, and S. S. Idem, 2013: Application of Electrical Resistivity Tomography in Mapping Subsurface Hydrocarbon Contamination. Earth Sci.Res., 2, 93-104, doi: 10.5539/esr.v2n1p93. [Link]

Barker, R. D., 1981: The offset system of electrical resistivity sounding and its use with a multicore cable. Geophys. Prospect., 29, 128-143, doi: 10.1111/j.13652478.1981.tb01015.x. [Link]

Barker, R. D., 1989: Depth of investigation of collinear symmetrical four-electrode arrays. Geophysics, 54, 1031-1037, doi: 10.1190/1.1442728. [Link]

Barker, R. D., 1992: A simple algorithm for electrical imaging of the subsurface. First Break, 10, 53-62, doi: 10.3997/1365-2397.1992004. [Link]

Bing, Z. and S. A. Greenhalgh, 1997: A synthetic study on crosshole resistivity imaging using different electrode arrays. Explor. Geophys., 28, 1-5, doi: 10.1071/ EG997001. [Link]

Bing, Z. and S. A. Greenhalgh, 2000: Cross-hole resistivity tomography using different electrode configurations. Geophys. Prospect., 48, 887-912, doi: 10.1046/j.13652478.2000.00220.x. [Link]

Bowling, J. C., D. L. Harry, A. B. Rodriguez, and C. Zheng, 2007: Integrated geophysical and geological investigation of a heterogeneous fluvial aquifer in Columbus Mississippi. J. Appl. Geophys., 62, 58-73, doi: 10.1016/j.jappgeo.2006.08.003. [Link]

Carrigan, C. R., X. Yang, D. J. LaBrecque, D. Larsen, D. Freeman, A. L. Ramirez, W. Daily, R. Aines, R. Newmark, J. Friedmann, and S. Hovorka, 2013: Electrical resistance tomographic monitoring of $\mathrm{CO}_{2}$ movement in deep geologic reservoirs. Int. J. Greenh. Gas Con., 18, 401-408, doi: 10.1016/j.ijggc.2013.04.016. [Link]

Chang, P.-Y., C. Chen, S.-K. Chang, T.-B. Wang, C.-Y. Wang, and S.-K. Hsu, 2012: An investigation into the debris flow induced by Typhoon Morakot in the Siaolin Area, Southern Taiwan, using the electrical resistivity imaging method. Geophys. J. Int., 188, 10121024, doi: 10.1111/j.1365-246X.2011.05310.x. [Link]

Christensen, N. B., D. Sherlock, and K. Dodds, 2006: Monitoring $\mathrm{CO}_{2}$ injection with cross-hole electrical resistivity tomography. Explor. Geophys., 37, 44-49, doi: 10.1071/EG06044. [Link]

Dahlin, T. and B. Zhou, 2004: A numerical comparison of 2D resistivity imaging with 10 electrode arrays. Geophys. Prospect., 52, 379-398, doi: 10.1111/j.13652478.2004.00423.x. [Link]

Daily, W. and E. Owen, 1991: Cross-borehole resistiv- ity tomography. Geophysics, 56, 1228-1235, doi: 10.1190/1.1443142. [Link]

Deceuster, J., J. Delgranche, and O. Kaufmann, 2006: 2D cross-borehole resistivity tomographies below foundations as a tool to design proper remedial actions in covered karst. J. Appl. Geophys., 60, 68-86, doi: 10.1016/j. jappgeo.2005.12.005. [Link]

Goes, B. J. M. and J. A. C. Meekes, 2004: An effective electrode configuration for the detection of DNAPLs with electrical resistivity tomography. J.Environ. Eng. Geophys., 9, 127-141, doi: 10.4133/JEEG9.3.127. [Link]

Greenhalgh, S., B. Zhou, and J. Zhe, 2000: Crosshole resistivity imaging of aquifer properties. Explor. Geophys., 31, 315-320, doi: 10.1071/EG00315. [Link]

Griffiths, D. H. and R. D. Barker, 1993: Two-dimensional resistivity imaging and modelling in areas of complex geology. J. Appl. Geophys., 29, 211-226, doi: 10.1016/0926-9851(93)90005-J. [Link]

Griffiths, D. H. and J. Turnbull, 1985: A multi-electrode array for resistivity surveying. First Break, 3, 16-20, doi: 10.3997/1365-2397.1985013. [Link]

Griffiths, D. H., J. Turnbull, and A. I. Olayinka, 1990: Two-dimensional resistivity mapping with a computer-controlled array. First Break, 8, 121-129, doi: 10.3997/1365-2397.1990008. [Link]

Guo, T. R.,L. T. Tong, L. W. Chiang, and C.H. Yang, 2011: A fracture study by using bipole-bipole cross-well logging. J. Appl. Geophys., 75, 203-210, doi: 10.1016/j. jappgeo.2011.07.012. [Link]

Halihan, T., S. Paxton, I. Graham, T. Fenstemaker, and M. Riley, 2005: Post-remediation evaluation of a LNAPL site using electrical resistivity imaging. J. Environ. Monit., 7, 283-287, doi: 10.1039/b416484a. [Link]

Leeson, A., H. F. Stroo, and P. C. Johnson, 2013: Groundwater remediation today and challenges and opportunities for the future. Groundwater, 51, 175-179, doi: 10.1111/gwat.12039. [Link]

Lin, C.-P., Y.-C. Hung, Z.-H. Yu, and P.-L. Wu, 2013: Investigation of abnormal seepages in an earth dam using resistivity tomography. J. GeoEngineering, 8, 61-70, doi: 10.6310/jog.2013.8(2).4. [Link]

Loke, M. H., 1994: The inversion of two-dimensional resistivity data. Ph.D. Thesis, University of Birmingham, United Kingdom.

Loke, M. H., P. B. Wilkinson, and J. E. Chambers, 2010a: Fast computation of optimized electrode arrays for 2D resistivity surveys. Comput. Geosci., 36, 1414-1426, doi: 10.1016/j.cageo.2010.03.016. [Link]

Loke, M. H., P. B. Wilkinson, and J. E. Chambers, 2010b: Parallel computation of optimized arrays for 2-D electrical imaging surveys. Geophys. J. Int., 183, 13021315, doi: 10.1111/j.1365-246x.2010.04796.x. [Link]

Loke, M. H., J. E. Chambers, D. F. Rucker, O. Kuras, and P. B. Wilkinson, 2013: Recent developments in 
the direct-current geoelectrical imaging method. $J$. Appl. Geophys., 95, 135-156, doi: 10.1016/j.jappgeo.2013.02.017. [Link]

Martínez-Pagán, P., Á. F. Cano, G. R. R. da Silva, and A. B. Olivares, 2010: 2-D Electrical Resistivity Imaging to Assess Slurry Pond Subsoil Pollution in the Southeastern Region of Murcia, Spain. J. Environ. Eng. Geophys., 15, 29-47, doi: 10.2113/JEEG15.1.29. [Link]

Petersen, T. and S. A. al Hagrey, 2009: Mapping root zones of small plants using surface and borehole resistivity tomography. The Leading Edge, 28, 1220-1224, doi: 10.1190/1.3249778. [Link]

Shima, H., 1992: 2-D and 3-D resistivity image reconstruction using crosshole data. Geophysics, 57, 1270-1281, doi: 10.1190/1.1443195. [Link]

Soupios, P. M., P. Georgakopoulos, N. Papadopoulos, V. Saltas, A. Andreadakis, F. Vallianatos, A. Sarris, and J. P. Makris, 2007a: Use of engineering geophysics to investigate a site for a building foundation. J. Geophys. Eng., 4, 94-103, doi: 10.1088/1742-2132/4/1/011. [Link]

Soupios, P., N. Papadopoulos, I. Papadopoulos, M. Kouli, F. Vallianatos, A. Sarris, and T. Manios, 2007b: Application of integrated methods in mapping waste disposal areas. Environ. Geol., 53, 661-675, doi: 10.1007/ s00254-007-0681-2. [Link]

Sugimoto, Y., 1999: Shallow high-resolution 2-D and 3-D electrical crosshole imaging. The Leading Edge, 18, 1425-1428, doi: 10.1190/1.1438244. [Link]

Tong, L.-T., K.-H. Lee, C.-K. Yeh, Y .-T. Hwang, and J.-M. Chien, 2013: Geophysical study of the Peinan Archaeological Site, Taiwan. J. Appl. Geophys., 89, 1-10, doi: 10.1016/j.jappgeo.2012.11.004. [Link]

Vaudelet, P., M. Schmutz, M. Pessel, M. Franceschi, R. Guérin, O. Atteia, A. Blondel, C. Ngomseu, S. Galaup, F. Rejiba, and P. Bégassat, 2011: Mapping of contami- nant plumes with geoelectrical methods. A case study in urban context. J. Appl. Geophys., 75, 738-751, doi: 10.1016/j.jappgeo.2011.09.023. [Link]

Wang, T.-P., C.-C. Chen, L.-T. Tong, P.-Y. Chang, Y.-C. Chen, T.-H. Dong, H.-C. Liu, C.-P. Lin, K.-H. Yang, C.-J. Ho, and S.-N. Cheng, 2015: Applying FDEM, ERT and GPR at a Site with Soil Contamination: A Case Study. J. Appl. Geophys., 121, 21-30, doi: 10.1016/j.jappgeo.2015.07.005. [Link]

Wilkinson, P. B., P. I. Meldrum, O. Kuras, J. E. Chambers, S. J. Holyoake, and R. D. Ogilvy, 2010: High-resolution electrical resistivity tomography monitoring of a tracer test in a confined aquifer. J. Appl. Geophys., 70, 268-276, doi: 10.1016/j.jappgeo.2009.08.001. [Link]

Yang, C.-H., T.-B. Wang, and H.-C. Liu, 2008: Detection of dump carbide using the resistivity image profiling method: Case study. Practice Periodical of Hazardous, Toxic, and Radioactive Waste Management, 12, 4046, doi: 10.1061/(ASCE)1090-025X(2008)12:1(40). [Link]

Yang, X., 1999: Stochastic inversion of 3-D ERT data. Ph.D. Thesis, The University of Arizona, Tucson, Arizona.

Zheng, C. and S. M. Gorelick, 2003: Analysis of solute transport in flow fields influenced by preferential flowpaths at the decimeter scale. Groundwater, 41, 142155, doi: 10.1111/j.1745-6584.2003.tb02578.x. [Link]

Zhou, B., 1998: Crosshole resistivity and acoustic velocity imaging: 2.5-D Helmholtz equation modeling and inversion. Ph.D. Thesis, Department of Geology and Geophysics, The University of Adelaide, Australia, $248 \mathrm{pp}$.

Zhou, B. and T. Dahlin, 2003: Properties and effects of measurement errors on 2D resistivity imaging surveying. Near Surface Geophysics, 1, 105-117, doi: 10.3997/1873-0604.2003001. [Link] 